\title{
Effect of Grinding Methods on Structural, Physicochemical, and Functional Properties of Insoluble Dietary Fiber from Orange Peel
}

\author{
Yanlong Liu, Lufeng Wang, Fengxia Liu, and Siyi Pan \\ Key Laboratory of Environment Correlative Dietology, Ministry of Education, College of Food Science and Technology, \\ Huazhong Agricultural University, Wuhan 430070, China
}

Correspondence should be addressed to Lufeng Wang; wanglf@mail.hzau.edu.cn

Received 16 December 2015; Revised 22 February 2016; Accepted 3 March 2016

Academic Editor: Angel Concheiro

Copyright (C) 2016 Yanlong Liu et al. This is an open access article distributed under the Creative Commons Attribution License, which permits unrestricted use, distribution, and reproduction in any medium, provided the original work is properly cited.

\begin{abstract}
This study evaluated the effect of grinding methods (regular laboratory milling, ultra centrifugal rotor milling, and ball milling) on structural, physicochemical, and functional properties of insoluble dietary fiber (IDF) fraction from orange peel. The results demonstrated that both ultra centrifugal milling and ball milling could effectively decrease average particle size of IDF fraction $(81.40 \mu \mathrm{m}$ and $19.63 \mu \mathrm{m}$, resp.). The matrix structure of IDF fraction was destroyed but FTIR structure had no major change after grinding. As particle size decreased, the bulk density and lightness of IDF fraction increased and a redistribution of fiber components from insoluble to soluble fractions was observed. Furthermore, ball milled IDF fraction exhibited significantly higher capacity to retard glucose diffusion and inhibit $\alpha$-amylase activity (35.09\%). This work would give useful insight into effect of grinding methods on properties and functions of orange peel IDF in food industry.
\end{abstract}

\section{Introduction}

Dietary fiber is a complex component of natural carbohydrate polymer which consists of variety of nonstarch polysaccharides such as cellulose, hemicelluloses, lignin, and pectin [1]. High dietary fiber consumption is associated with the prevention and treatment of obesity, diabetes, colorectal cancer, and atherosclerosis [2]. In vivo and in vitro studies have shown that dietary fiber might retard the utilization of sugars and control the postprandial blood glucose levels $[3,4]$. Foods supplemented with dietary fibers are regarded as fitness-promoting and low in calories, cholesterol, and fat [5].

Orange is one of the most important fruit crops in the world with an annual production more than 122.5 million tons [6]. A large number of orange byproducts are produced during the processing, which may be a potential source of dietary fiber, but now they constitute a severe environmental problem [7]. Besides, orange peel is used to produce pectin, but the insoluble fiber fraction is still left, which needs to be further processed to bring economic benefit. Orange peel dietary fiber has been reported to have potential hypoglycemic effect by delaying glucose diffusion and inhibiting $\alpha$-amylase activity [8]. Various processing steps lead to the modification of fiber compositions and microstructure, which in turn lead to changes in the functional and nutritional properties of dietary fiber $[9,10]$. Up to now, although some studies have been conducted on orange peel fiber, most of them concentrated in the pretreatment and extraction methods $[7,9]$. However, to the best of our knowledge, little work focused on the effect of grinding methods on properties and functions of orange peel fiber.

Superfine grinding is a new type of food processing technology, which is employed to produce powders with outstanding properties such as high solubility, dispersion, adsorption, and chemical reactivity [11]. Recently, superfine grinding has been used in biotechnology and food material but rarely [12]. Grinding could decrease particle size of dietary fiber, therefore modifying the physicochemical properties of the fiber [13]. Because the physicochemical properties of dietary fiber usually provide clues to their potential physiological effects, it is hence interesting to 
investigate the effect of grinding on physicochemical and functional properties of dietary fiber [14]. Previous studies have demonstrated that superfine grinding could enhance antioxidant properties of dietary fiber [15]. However, effect of superfine grinding on some other functional properties of dietary fiber, such as hypoglycemic effect, is far from clear. Rotor mill and ball mill are the most common types of grinders used in the milling of agricultural materials and food processing. Ball mill is also used for superfine grinding [15]. These grinders are easily available at a reasonable price and are simple to operate and maintain.

The objective of this study was to evaluate the effect of grinding methods (regular laboratory milling, ultra centrifugal rotor milling, and ball milling) on structural characteristics and physicochemical and functional properties of insoluble fiber from orange peel. The results of this work might give insight into effect of grinding methods on properties of orange peel dietary fiber and provide a reference for its further applications.

\section{Materials and Methods}

2.1. Sample Preparation. Fresh oranges (Citrus sinensis (L.) Osbeck) were purchased from a commercial orchard in Zigui, Hubei Province, China. The orange peels were washed and milled into pomace and then thoroughly mixed with distilled water in a solid-liquid ratio of $1: 5$. The mixture was heated in water bath at $90^{\circ} \mathrm{C}$ for $2 \mathrm{~h}$ under constant stirring of $120 \mathrm{rpm}$ and centrifuged at $2000 \times \mathrm{g}$ for $20 \mathrm{~min}$ to separate insoluble fraction. The precipitate was washed with distilled water and collected by pumping filtration, which was insoluble dietary fiber (IDF) fraction. The IDF fraction was freezedried (LGJ-18S, Songyuan Huaxing, Beijing, China) for $48 \mathrm{~h}$ to obtain dry IDF fraction sample. The freeze-dried IDF fraction was premilled using a regular laboratory mill (QE$100 \mathrm{~g}$, Yili Co., Jinhua, China) for $1 \mathrm{~min}$, and the sample was named RMDF. The RMDF was divided into three parts. One part was used for determinations, and the other two parts were further ground in two different grinding methods using ultra centrifugal rotor mill (ZM 200, Retsch, Haan, Germany) and planetary ball mill (XQM-2L, Daran, Nanjing, China). For the ultra centrifugal milling, the grinding was carried in the milling chamber at a rotating speed of $10000 \mathrm{rpm}$, and the sample was named UMDF. For the ball milling, fiber sample and stainless steel balls (10 $\mathrm{mm}$ in diameter) were mixed at a volume ratio of $1: 1$ in a $500 \mathrm{~mL}$ stainless steel grinding bowl and were ground at $200 \mathrm{rpm}$ for $2 \mathrm{~h}$, and the sample was named BMDF. The powder was hermetically kept in a desiccator for further experiments.

2.2. Determination of Dietary Fiber Contents. Total dietary fiber (TDF), IDF, and soluble dietary fiber (SDF) contents in IDF fraction samples were determined by an enzymaticgravimetric procedure according to AOAC method 991.43 [16].

2.3. Particle Size Analysis. The particle size of the fiber was determined using a Malvern laser particle analyzer (Mastersizer 2000, Malvern, Worcestershire, UK).
2.4. Fourier Transform Infrared Spectroscopy (FTIR). FTIR spectra were collected using a FTIR spectrometer (Nicolet 470, Thermo Scientific, Waltham, USA) over the range 4000$400 \mathrm{~cm}^{-1}$ by the potassium bromide $(\mathrm{KBr})$ pellet method [17]. For each sample, 32 scans were averaged with a spectral resolution of $4 \mathrm{~cm}^{-1}$.

2.5. Scanning Electron Microscope (SEM). The dietary fibers were placed on a specimen holder by a double-sided carbon tape and coated with gold [18]. The microstructures of fibers were observed using a scanning electron microscope (JSM6390LV, JEOL, Tokyo, Japan).

2.6. Color Determination. The color values of dietary fibers were expressed using CIELab coordinates $\left(L^{*}, a^{*}\right.$, and $\left.b^{*}\right)$, where values of $L^{*}, a^{*}$, and $b^{*}$ represented lightness, redness $\left(a^{*}>0\right)$, or greenness $\left(a^{*}<0\right)$ and yellowness $\left(b^{*}>0\right)$ or blueness $\left(b^{*}<0\right)$, respectively [19]. The color values of different dietary fibers were measured by a colorimeter (CR400, Konica Minolta, Tokyo, Japan).

2.7. Bulk Density. A known weight of fiber sample was gently filled in a $10 \mathrm{~mL}$ graduated cylinder and the volume was recorded. The bulk density $(\mathrm{g} / \mathrm{mL})$ of dietary fiber was defined as the ratio of weight and volume [20].

2.8. Effect of IDF Fraction on Glucose Diffusion. The effect of different IDF fractions on glucose diffusion was determined by the method reported by $\mathrm{Ou}$ et al. [4] with slight modifications. Dietary fiber $(0.5 \mathrm{~g})$ was mixed with $25 \mathrm{~mL}$ of glucose solution $(100 \mathrm{mmol} / \mathrm{L})$ and dialyzed in a dialysis bag with a cutoff molecular weight of 12000 against $200 \mathrm{~mL}$ of distilled water at $37^{\circ} \mathrm{C}$. The glucose contents in the dialysate were determined at 15, 30, 60, 90, 120, and $180 \mathrm{~min}$ using a glucose assay kit (Rongsheng Biotech, Shanghai, China). A control experiment was also carried out without the addition of dietary fiber.

The experimental data (glucose content of the dialysate and time) were fitted with a parabolic equation [4]:

$$
y=a x^{2}+b x+c
$$

where $y$ is the glucose content of the dialysate ( $\mu \mathrm{mol}) ; x$ is time ( $\mathrm{min}) ; a, b$, and $c$ are coefficients. The equation to calculate the diffusion rate $\left(y^{\prime}\right)$ at any time is

$$
y^{\prime}=2 a x+b
$$

When $x$ is close to $0, y^{\prime}=$ the maximum diffusion rate of glucose $\left(r_{\max }\right)=b$.

2.9. $\alpha$-Amylase Activity Inhibition Ratio ( $\alpha$-AAIR). Dietary fiber ( $1 \mathrm{~g}$ ) was mixed with $0.4 \mathrm{~g}$ of $\alpha$-amylase (A3176, Sigma, Saint Louis, USA) and $100 \mathrm{~mL} 4 \%$ potato starch solution $(0.05 \mathrm{~mol} / \mathrm{L}$ phosphate buffer, $\mathrm{pH} 6.5)$ at $37^{\circ} \mathrm{C}$ for $30 \mathrm{~min}$. $\mathrm{NaOH}(0.1 \mathrm{~mol} / \mathrm{L})$ was added to terminate the starch degradation. After centrifugation at $4000 \times \mathrm{g}$ for $20 \mathrm{~min}$, the glucose contents were determined using a glucose assay kit. A control experiment was carried out without the addition of dietary 


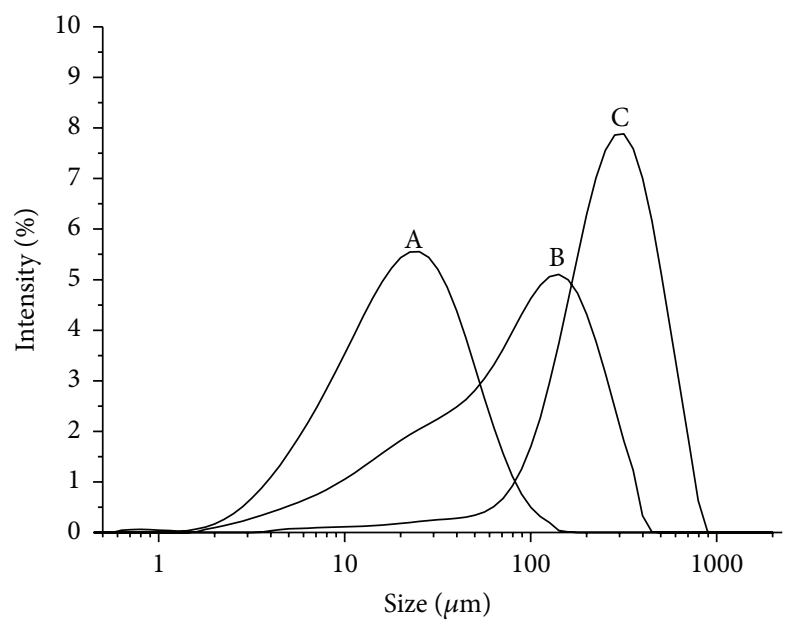

FIGURE 1: Particle size distributions of the IDF fraction powder: (A) ball milled IDF fraction, (B) ultra centrifugal milled IDF fraction, and $(\mathrm{C})$ regular milled IDF fraction.

fiber. The $\alpha$-amylase inhibition activity ratio (\%) was defined as the percentage decrease in the glucose production rate over the control [5].

2.10. Statistical Analysis. The results were expressed as means \pm standard deviation of five replicates. One-way analysis of variance (ANOVA) with Duncan's tests was used to analyze differences between means. $p<0.05$ was considered to be statistically significant. The statistical program SPSS Version 19.0 (SPSS Inc., Chicago, USA) was used to perform the statistical calculations.

\section{Results and Discussion}

3.1. Particle Size. The particle size distributions of the IDF fraction powder obtained by different grinding methods are shown in Figure 1. The particle sizes of RMDF, UMDF, and $\mathrm{BMDF}$ were distributed in a range from $3.99 \mu \mathrm{m}$ to $796.21 \mu \mathrm{m}$, from $1.78 \mu \mathrm{m}$ to $399.05 \mu \mathrm{m}$, and from $0.63 \mu \mathrm{m}$ to $158.87 \mu \mathrm{m}$, respectively. $D_{50}$ is considered to be the average median diameter which is representative of the degree of powder cohesiveness [21]. There were significant differences $(p<0.05)$ in average median diameter among RMDF $(257.66 \mu \mathrm{m}), \mathrm{UMDF}(81.40 \mu \mathrm{m})$, and BMDF $(19.63 \mu \mathrm{m})$. The results indicated that both ultra centrifugal milling and ball milling could effectively decrease the average particle size of IDF fraction, and ball milling worked better. Finer particles tended to have a greater number of particles per unit weight, indicating a higher potential for achieving homogeneity when mixed with other powder additives [22]. Ultra-fine IDF fraction powder is easier to enter into the structure of foods, which has higher dispersibility as additive in food processing.

\subsection{Structural Characteristic}

3.2.1. FTIR Spectra. FTIR spectra of IDF fractions prepared by different grinding methods are presented in Figure 2. All samples showed two characteristic absorption peaks

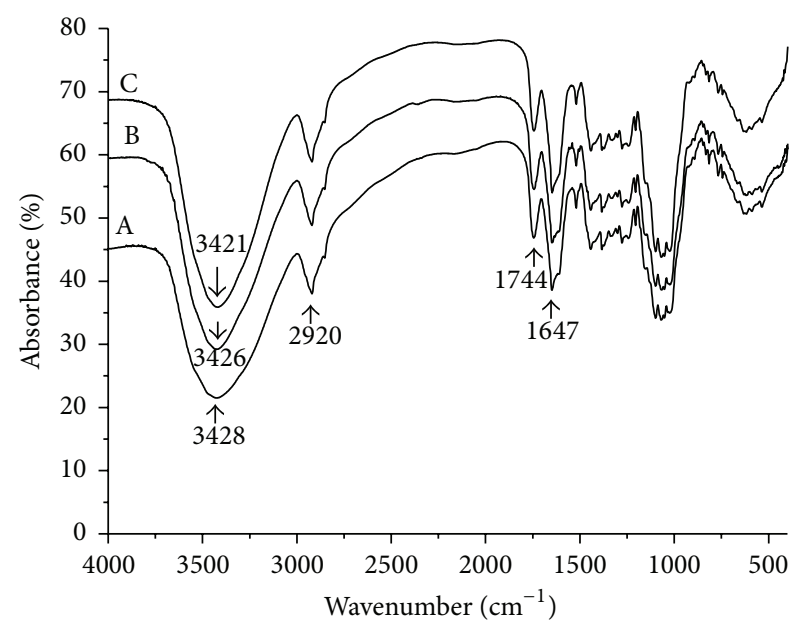

FIGURE 2: FTIR spectra of the different IDF fractions: (A) regular milled IDF fraction, (B) ultra centrifugal milled IDF fraction, and (C) ball milled IDF fraction.

at $3421-3428 \mathrm{~cm}^{-1}$ (O-H stretching vibration of hydroxyl group) and $2920 \mathrm{~cm}^{-1}$ (C-H stretching vibration of methyl and methylene), which revealed the presence of the typical structure of polysaccharide compounds [23]. The characteristic peaks at $1744 \mathrm{~cm}^{-1}$ corresponded to carbonyl group stretching vibration of ester group and peaks at $1647 \mathrm{~cm}^{-1}$ belonged to aromatic benzene in lignin, which were observed in all samples [24]. Compared with FTIR spectra of RMDF, the characteristic absorption peak of BMDF shifted from $3428 \mathrm{~cm}^{-1}$ to $3421 \mathrm{~cm}^{-1}$. The shift indicated that the mechanical force during ball milling could break the intramolecular hydrogen bonds [25], which might be attributed to cellulose degradation [24]. In addition, the wavelength of other absorption peaks did not shift. There was no significant change in peak shape of FTIR spectra, which indicated no fundamental change in the main components after grinding, ensuring that the active ingredients of dietary fiber were not destroyed during the grinding treatment.

3.2.2. Microstructures. Microstructures of ground IDF fraction were observed by SEM and micrographs are presented in Figure 3. It was observed that the particle size of UMDF and BMDF was smaller than that of RMDF, which was in accordance with the results of particle size measurement. Grinding led not only to reduction of particle size, but also to a deep structural modification of fiber. SEM images of RMDF revealed the presence of porosity structure with a greater number of cracks, while the porosity structure of UMDF and BMDF partly disappeared. Raghavendra et al. [26] reported that the grinding operation resulted in the rupture of the matrix structure of fiber from coconut residue, which was in agreement with the results in this study. The change of microstructures of UMDF and BMDF was attributed to the matrix structure that was broken under strong mechanical, which might have an influence on the physicochemical properties of IDF fraction. 


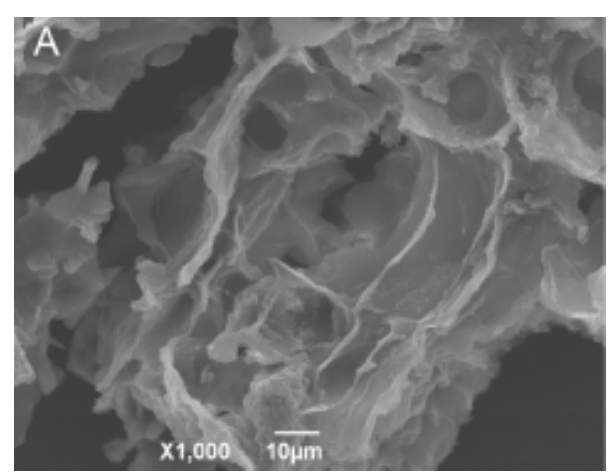

(a)

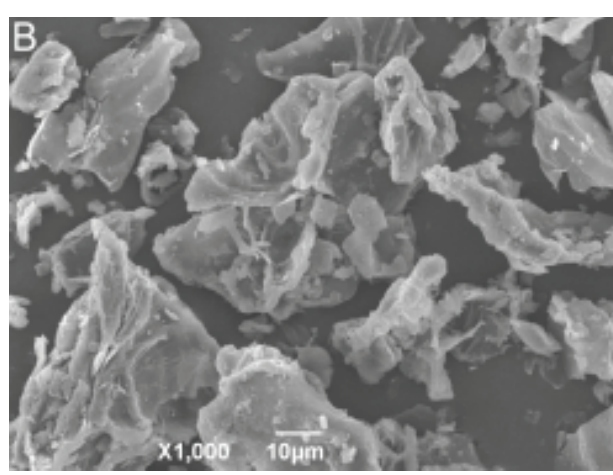

(b)

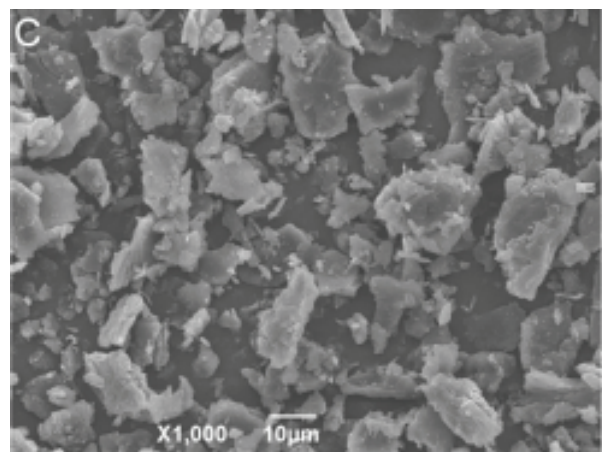

(c)

FIGURE 3: Scanning electron micrographs (1000x) of different IDF fractions: (a) regular milled IDF fraction, (b) ultra centrifugal milled IDF fraction, and (c) ball milled IDF fraction.

TABLE 1: Effects of grinding on physicochemical properties of IDF fraction.

\begin{tabular}{lccc}
\hline Sample & RMDF & UMDF & BMDF \\
\hline IDF $(\mathrm{g} / 100 \mathrm{~g})$ & $76.92 \pm 0.22^{\mathrm{a}}$ & $74.59 \pm 0.24^{\mathrm{b}}$ & $72.28 \pm 0.17^{\mathrm{c}}$ \\
SDF $(\mathrm{g} / 100 \mathrm{~g})$ & $1.33 \pm 0.05^{\mathrm{c}}$ & $3.05 \pm 0.05^{\mathrm{b}}$ & $4.08 \pm 0.08^{\mathrm{a}}$ \\
TDF $(\mathrm{g} / 100 \mathrm{~g})$ & $78.25 \pm 0.21^{\mathrm{a}}$ & $77.64 \pm 0.27^{\mathrm{b}}$ & $76.36 \pm 0.18^{\mathrm{c}}$ \\
$L^{*}$ & $83.41 \pm 0.19^{\mathrm{c}}$ & $87.36 \pm 0.15^{\mathrm{b}}$ & $89.15 \pm 0.21^{\mathrm{a}}$ \\
$a^{*}$ & $0.90 \pm 0.04^{\mathrm{a}}$ & $0.12 \pm 0.02^{\mathrm{b}}$ & $-0.72 \pm 0.04^{\mathrm{c}}$ \\
$b^{*}$ & $26.18 \pm 0.15^{\mathrm{a}}$ & $21.77 \pm 0.21^{\mathrm{b}}$ & $18.66 \pm 0.23^{\mathrm{c}}$ \\
Bulk density $(\mathrm{g} / \mathrm{mL})$ & $0.12 \pm 0.00^{\mathrm{c}}$ & $0.21 \pm 0.00^{\mathrm{b}}$ & $0.25 \pm 0.00^{\mathrm{a}}$ \\
\hline
\end{tabular}

The values are the mean \pm SD. Values with different letters in the same row are significantly different $(p<0.05)$.

\subsection{Physicochemical Properties}

3.3.1. Dietary Fiber Contents. The dietary fiber contents in different samples are shown in Table 1. The IDF contents in fiber sample decreased from $76.92 \mathrm{~g} / 100 \mathrm{~g}$ to $74.59 \mathrm{~g} / 100 \mathrm{~g}$ and $72.28 \mathrm{~g} / 100 \mathrm{~g}$ after ultra centrifugal milling and ball milling while the SDF contents increased from $1.33 \mathrm{~g} / 100 \mathrm{~g}$ to $3.05 \mathrm{~g} / 100 \mathrm{~g}$ and $4.08 \mathrm{~g} / 100 \mathrm{~g}$, respectively, indicating that grinding caused a redistribution of fiber components in orange peel fiber. Besides, the TDF content after grinding decreased slightly. The decrease of IDF and TDF contents after grinding might be caused by the degradation of hemicellulose, cellulose, and lignin, which were turned into SDF fraction and some other small molecular substances [15]. The IDF contents in ground orange peel IDF fraction samples in this study were similar to previous results $(74.62 \mathrm{~g} / 100 \mathrm{~g})$
[7]. According to Larrauri [27], commercialized dietary fiber products are characterized by TDF content higher than $50 \mathrm{~g} / 100 \mathrm{~g}$. In this respect, the high dietary fiber content in orange peel IDF fraction indicates that it has potential to be a commercialized product.

3.3.2. Color. Possible color changes would influence the organoleptic properties of orange peel samples and would limit their potential applications [10]. Table 1 displays the CIELab parameters $\left(L^{*}, a^{*}\right.$, and $\left.b^{*}\right)$ of differently ground IDF fractions. Compared with RMDF, UMDF and BMDF were characterized by significantly $(p<0.05)$ higher $L^{*}$ values and lower $a^{*}$ values and $b^{*}$ values, which suggested that the lightness of BMDF and UMDF increased while redness and yellowness decreased. It was indicated that the 
TABLE 2: Effect of different IDF fractions on glucose diffusion and $\alpha$-amylase activity.

\begin{tabular}{lcccccc}
\hline \multirow{2}{*}{ Sample } & & \multicolumn{5}{c}{ Glucose content in dialysate $(\mu \mathrm{mol})$} \\
& $15 \mathrm{~min}$ & $30 \mathrm{~min}$ & $60 \mathrm{~min}$ & $90 \mathrm{~min}$ & $120 \mathrm{~min}$ & $180 \mathrm{~min}$ \\
\hline RMDF & $358.79 \pm 4.90^{\mathrm{b}}$ & $654.29 \pm 5.51^{\mathrm{b}}$ & $1092.05 \pm 12.95^{\mathrm{b}}$ & $1436.86 \pm 10.94^{\mathrm{b}}$ & $1715.42 \pm 20.27^{\mathrm{b}}$ & $2004.94 \pm 12.80^{\mathrm{b}}$ \\
UMDF & $349.12 \pm 5.19^{\mathrm{b}}$ & $608.65 \pm 8.71^{\mathrm{c}}$ & $1031.23 \pm 8.64^{\mathrm{c}}$ & $1395.90 \pm 8.96^{\mathrm{c}}$ & $1640.44 \pm 10.97^{\mathrm{c}}$ & $1969.40 \pm 12.65^{\mathrm{c}}$ \\
BMDF & $329.78 \pm 4.96^{\mathrm{c}}$ & $582.08 \pm 4.03^{\mathrm{d}}$ & $982.21 \pm 11.07^{\mathrm{d}}$ & $1348.37 \pm 9.44^{\mathrm{d}}$ & $1599.32 \pm 10.05^{\mathrm{d}}$ & $1943.08 \pm 11.78^{\mathrm{c}}$ \\
Control & $421.06 \pm 10.02^{\mathrm{a}}$ & $733.36 \pm 11.04^{\mathrm{a}}$ & $1254.01 \pm 9.91^{\mathrm{a}}$ & $1637.09 \pm 11.13^{\mathrm{a}}$ & $1913.46 \pm 8.54^{\mathrm{a}}$ & $2165.73 \pm 10.84^{\mathrm{a}}$ \\
\hline
\end{tabular}

The values are the mean \pm SD. Values with different letters in the same column are significantly different $(p<0.05)$.

TABLE 3: Glucose diffusion equation with different IDF fractions.

\begin{tabular}{llcc}
\hline Sample & \multicolumn{1}{c}{ Glucose diffusion equation } & $R^{2}$ & Maximum diffusion rate $(\mu \mathrm{mol} / \mathrm{min})$ \\
\hline RMDF & $y=-0.0489 x^{2}+19.383 x+96.157$ & 0.9996 & 19.383 \\
$\mathrm{UMDF}$ & $y=-0.0436 x^{2}+18.264 x+90.706$ & 0.9997 & 18.264 \\
BMDF & $y=-0.0401 x^{2}+17.544 x+80.825$ & 0.9997 & 17.544 \\
Control & $y=-0.0623 x^{2}+22.626 x+104.27$ & 0.9998 & 22.626 \\
\hline
\end{tabular}

The diffusion equation is fitted according to five-replicate data. In the diffusion equation, $y$ is the glucose content of the dialysate ( $\mu \mathrm{mol})$, and $x$ is time (min).

particle size might have a significant effect on lightness of powder [28]. In this study, it could be found that $L^{*}$ values increased significantly with the decrease in particle size of IDF fraction, which was similar to the results of $\mathrm{Hu}$ et al. [28]. It is probably due to more uniform distribution of finer fiber fractions after the fine grinding process [29]. The lightness with high $L^{*}$ value in raw ingredients plays a crucial role in food development due to consumer preferences [30]. This implied that ball milling might be more beneficial to the application of IDF fraction in light colored food because of the higher lightness.

3.3.3. Bulk Density. The bulk densities of UMDF $(0.21 \mathrm{~g} / \mathrm{mL})$ and BMDF $(0.25 \mathrm{~g} / \mathrm{mL})$ were significantly $(p<0.05)$ higher than that of RMDF $(0.12 \mathrm{~g} / \mathrm{mL})$, respectively, which indicated that ultra centrifugal milling and ball milling could increase the bulk density of IDF fraction. Bulk density depends on the chemical and physical characteristics of the solid and on the proportion of air volume which is affected by the collapse of the matrix [31]. Besides, density is related to the particle size and distribution, and the larger particle size of dietary fiber is associated with lower bulk density [13]. In this study, the ball milling and ultra centrifugal milling partly destroyed the matrix structure of orange peel IDF fraction and thus resulted in smaller particle size. The higher bulk densities of BMDF and UMDF might be attributed to high homogeneousness of superfine particle, which might lead to a probable decrease of the interparticle voids [32]. The superfine ground dietary fiber with higher bulk density was beneficial to filling in preparing tablets or capsule products [33].

\subsection{Functional Properties}

3.4.1. Effect of Different IDF Fractions on Glucose Diffusion. Glucose dialysis is a useful way to predict the in vitro effect of dietary fiber on the delay of glucose absorption in gastrointestinal tract [34]. Effect of different IDF fractions on glucose diffusion is presented in Table 2. All dietary fiber samples effectively delayed glucose diffusion at 15-180 min compared with control, and the glucose content in the dialysate with $\mathrm{BMDF}$ was the lowest during the whole diffusion processing. According to Table 3, the maximum diffusion rate of BMDF was the lowest, which might contribute to the lower glucose content in the dialysate. The results indicated that ball milling enhanced the effect of IDF fraction on retarding glucose diffusion. Similarly, Chen et al. [5] reported that peach IDF by microfluidization treatment decreased the glucose diffusion rate compared with the untreated one. The physical obstacle by fiber particles towards glucose molecules and entrapment of glucose molecules within the fiber may contribute to the delay of glucose diffusion [34]. Besides, superfine powder of dietary fiber has higher dispersibility in food systems [15]. In this study, BMDF with smaller particle size tended to have a greater number of particles per unit weight and then distributed more homogeneously in the glucose-dietary fiber system, which consequently resulted in greater physical obstacle and delay effect on the glucose diffusion. From the results in this in vitro study, the enhanced abilities of the ball milled orange peel IDF fraction to delay glucose diffusion implied that it might have potential in decreasing the absorption rate of glucose in intestine.

3.4.2. $\alpha$-Amylase Activity Inhibition Ratio. The $\alpha$-AAIR is an indicative index of the physiological properties of dietary fiber. UMDF and BMDF inhibited $\alpha$-amylase activity by $17.61 \%$ and $35.09 \%$ (Table 4 ), respectively, which was significantly $(p<0.05)$ higher than RMDF (10.33\%). $\alpha$-AAIR of orange peel IDF fraction increased by 2.4 -fold after ball milling compared with regular milling, which was within the range of oat IDF (30.64\%) and peach IDF $(47.07 \%)$ after microfluidization treatment [5]. Ball milling decreased particle size and caused higher dispersibility and physical interference of IDF fraction due to a greater number of particles per unit weight. It was speculated that BMDF might wrap and embed more $\alpha$-amylase and starch molecules in the dietary fiber network and decrease the contact between 
TABLE 4: Effect of different IDF fractions on $\alpha$-amylase activity inhibition ratio.

\begin{tabular}{lc}
\hline Sample & $\alpha$-Amylase activity inhibition ratio (\%) \\
\hline RMDF & $10.33 \pm 0.14^{\mathrm{c}}$ \\
UMDF & $17.61 \pm 0.39^{\mathrm{b}}$ \\
BMDF & $35.09 \pm 0.36^{\mathrm{a}}$
\end{tabular}

The values are the mean \pm SD. Values with different letters in the same column are significantly different $(p<0.05)$.

$\alpha$-amylase and starch molecules, which decreased $\alpha$-amylase activity [20]. The enhanced functional capacities of ball milled orange peel IDF fraction to delay glucose diffusion and inhibit $\alpha$-amylase activity implied that it might have great potential in decreasing the rate of starch digestion and even the postprandial serum glucose level.

\section{Conclusion}

In this study, both ultra centrifugal milling and ball milling could effectively decrease the particle size of orange peel IDF fraction. Grinding caused a redistribution of fiber components from insoluble to soluble fractions in orange peel dietary fiber. The changes in physicochemical properties after grinding might be attributed to the change of matrix structure and particle size of IDF fraction. Ball milled IDF fraction exhibited higher glucose diffusion retarding effect and $\alpha$ amylase activity inhibition ratio in this study. Therefore, ball milling treatment improved the functionality of IDF fraction, which could be used as a novel fiber-rich ingredient in functional foods. The grinding study on orange peel IDF fraction will give useful insight into its physicochemical and functional properties and provide a reference for further applications in food industry.

\section{Competing Interests}

The authors declare that there is no conflict of interests regarding the publication of this paper.

\section{Acknowledgments}

This work was supported by Scientific Research Project of Chinese Public Welfare Industry (Agriculture) (no. 201303076) and Natural Science Foundation of Hubei Province, China (no. 2015CFB390).

\section{References}

[1] A. Abirami, G. Nagarani, and P. Siddhuraju, "Measurement of functional properties and health promoting aspects-glucose retardation index of peel, pulp and peel fiber from Citrus hystrix and Citrus maxima," Bioactive Carbohydrates and Dietary Fibre, vol. 4, no. 1, pp. 16-26, 2014.

[2] J. W. Anderson, P. Baird, R. H. Davis Jr. et al., "Health benefits of dietary fiber," Nutrition Reviews, vol. 67, no. 4, pp. 188-205, 2009.

[3] M. Chandalia, A. Garg, D. Lutjohann, K. Von Bergmann, S. M. Grundy, and L. J. Brinkley, "Beneficial effects of high dietary fiber intake in patients with type 2 diabetes mellitus," The New England Journal of Medicine, vol. 342, no. 19, pp. 1392-1398, 2000.

[4] S. Ou, K.-C. Kwok, Y. Li, and L. Fu, "In vitro study of possible role of dietary fiber in lowering postprandial serum glucose," Journal of Agricultural and Food Chemistry, vol. 49, no. 2, pp. 1026-1029, 2001.

[5] J. Chen, D. Gao, L. Yang, and Y. Gao, "Effect of microfluidization process on the functional properties of insoluble dietary fiber," Food Research International, vol. 54, no. 2, pp. 1821-1827, 2013.

[6] N. Jiang, L.-F. Jin, J. A. Teixeira da Silva et al., "Activities of enzymes directly related with sucrose and citric acid metabolism in citrus fruit in response to soil plastic film mulch," Scientia Horticulturae, vol. 168, pp. 73-80, 2014.

[7] F. R. Marín, C. Soler-Rivas, O. Benavente-García, J. Castillo, and J. A. Pérez-Alvarez, "By-products from different citrus processes as a source of customized functional fibres," Food Chemistry, vol. 100, no. 2, pp. 736-741, 2007.

[8] C.-F. Chau, Y.-L. Huang, and M.-H. Lee, "In vitro hypoglycemic effects of different insoluble fiber-rich fractions prepared from the peel of Citrus sinensis L. cv. liucheng," Journal of Agricultural and Food Chemistry, vol. 51, no. 22, pp. 6623-6626, 2003.

[9] P. Peerajit, N. Chiewchan, and S. Devahastin, "Effects of pretreatment methods on health-related functional properties of high dietary fibre powder from lime residues," Food Chemistry, vol. 132, no. 4, pp. 1891-1898, 2012.

[10] M. C. Garau, S. Simal, C. Rosselló, and A. Femenia, "Effect of air-drying temperature on physico-chemical properties of dietary fibre and antioxidant capacity of orange (Citrus aurantium v. Canoneta) by-products," Food Chemistry, vol. 104, no. 3, pp. 1014-1024, 2007.

[11] G.-C. Wu, M. Zhang, Y.-Q. Wang, K. J. Mothibe, and W.-X. Chen, "Production of silver carp bone powder using superfine grinding technology: suitable production parameters and its properties," Journal of Food Engineering, vol. 109, no. 4, pp. 730$735,2012$.

[12] X. Zhao, H. Zhu, J. Chen, and Q. Ao, "FTIR, XRD and SEM analysis of ginger powders with different size," Journal of Food Processing and Preservation, vol. 39, no. 6, pp. 2017-2026, 2015.

[13] M. F. de Escalada Pla, P. González, P. Sette, F. Portillo, A. M. Rojas, and L. N. Gerschenson, "Effect of processing on physicochemical characteristics of dietary fibre concentrates obtained from peach (Prunus persica L.) peel and pulp," Food Research International, vol. 49, no. 1, pp. 184-192, 2012.

[14] S.-C. Wu, S.-H. Wu, and C.-F. Chau, "Improvement of the hypocholesterolemic activities of two common fruit fibers by micronization processing," Journal of Agricultural and Food Chemistry, vol. 57, no. 12, pp. 5610-5614, 2009.

[15] K. X. Zhu, S. Huang, W. Peng, H. F. Qian, and H. M. Zhou, "Effect of ultrafine grinding on hydration and antioxidant properties of wheat bran dietary fiber," Food Research International, vol. 43, no. 4, pp. 943-948, 2010.

[16] AOAC, Official Methods of Analysis of AOAC International, Association of Official Analytical Chemists, Gaithersburg, Md, USA, 17th edition, 2000.

[17] J. A. Sánchez-Márquez, R. Fuentes-Ramírez, I. Cano-Rodríguez et al., "Membrane made of cellulose acetate with polyacrylic acid reinforced with carbon nanotubes and its applicability for chromium removal," International Journal of Polymer Science, vol. 2015, Article ID 320631, 12 pages, 2015.

[18] L. Kong, L. Yu, T. Feng, X. Yin, T. Liu, and L. Dong, "Physicochemical characterization of the polysaccharide from Bletilla 
striata: effect of drying method," Carbohydrate Polymers, vol. 125, pp. 1-8, 2015.

[19] J. Zhang and Z.-W. Wang, "Soluble dietary fiber from Canna edulis Ker by-product and its physicochemical properties," Carbohydrate Polymers, vol. 92, no. 1, pp. 289-296, 2013.

[20] C.-F. Chau, Y.-T. Wang, and Y.-L. Wen, "Different micronization methods significantly improve the functionality of carrot insoluble fibre," Food Chemistry, vol. 100, no. 4, pp. 1402-1408, 2007.

[21] Z. Zhang, H. Song, Z. Peng, Q. Luo, J. Ming, and G. Zhao, "Characterization of stipe and cap powders of mushroom (Lentinus edodes) prepared by different grinding methods," Journal of Food Engineering, vol. 109, no. 3, pp. 406-413, 2012.

[22] C. K. Riley, S. A. Adebayo, A. O. Wheatley, and H. N. Asemota, "Surface properties of yam (Dioscorea sp.) starch powders and potential for use as binders and disintegrants in drug formulations," Powder Technology, vol. 185, no. 3, pp. 280-285, 2008.

[23] X. Yan, R. Ye, and Y. Chen, "Blasting extrusion processing: the increase of soluble dietary fiber content and extraction of soluble-fiber polysaccharides from wheat bran," Food Chemistry, vol. 180, pp. 106-115, 2015.

[24] M. Ma and T. Mu, "Modification of deoiled cumin dietary fiber with laccase and cellulase under high hydrostatic pressure," Carbohydrate Polymers, vol. 136, pp. 87-94, 2016.

[25] X. Zhao, H. Zhu, G. Zhang, and W. Tang, "Effect of superfine grinding on the physicochemical properties and antioxidant activity of red grape pomace powders," Powder Technology, vol. 286, pp. 838-844, 2015.

[26] S. N. Raghavendra, S. R. Ramachandra Swamy, N. K. Rastogi, K. S. M. S. Raghavarao, S. Kumar, and R. N. Tharanathan, "Grinding characteristics and hydration properties of coconut residue: a source of dietary fiber," Journal of Food Engineering, vol. 72, no. 3, pp. 281-286, 2006.

[27] J. A. Larrauri, "New approaches in the preparation of high dietary fibre powders from fruit by-products," Trends in Food Science \& Technology, vol. 10, no. 1, pp. 3-8, 1999.

[28] J. Hu, Y. Chen, and D. Ni, "Effect of superfine grinding on quality and antioxidant property of fine green tea powders," LWT_Food Science and Technology, vol. 45, no. 1, pp. 8-12, 2012.

[29] M. Niu, G. Hou, B. Lee, and Z. Chen, "Effects of fine grinding of millfeeds on the quality attributes of reconstituted wholewheat flour and its raw noodle products," LWT-Food Science and Technology, vol. 57, no. 1, pp. 58-64, 2014.

[30] J. Yang, A. Xiao, and C. Wang, "Novel development and characterisation of dietary fibre from yellow soybean hulls," Food Chemistry, vol. 161, pp. 367-375, 2014.

[31] B. Koç, İ. Eren, and F. K. Ertekin, "Modelling bulk density, porosity and shrinkage of quince during drying: the effect of drying method," Journal of Food Engineering, vol. 85, no. 3, pp. 340-349, 2008.

[32] X. Zhao, Z. Yang, G. Gai, and Y. Yang, "Effect of superfine grinding on properties of ginger powder," Journal of Food Engineering, vol. 91, no. 2, pp. 217-222, 2009.

[33] F. O. Costa, A. A. C. C. Pais, and J. J. S. Sousa, "Analysis of formulation effects in the dissolution of ibuprofen pellets," International Journal of Pharmaceutics, vol. 270, no. 1-2, pp. 919, 2004.

[34] G. López, G. Ros, F. Rincón, M. J. Periago, M. C. Martínez, and J. Ortuño, "Relationship between physical and hydration properties of soluble and insoluble fiber of artichoke," Journal of
Agricultural and Food Chemistry, vol. 44, no. 9, pp. 2773-2778, 1996. 

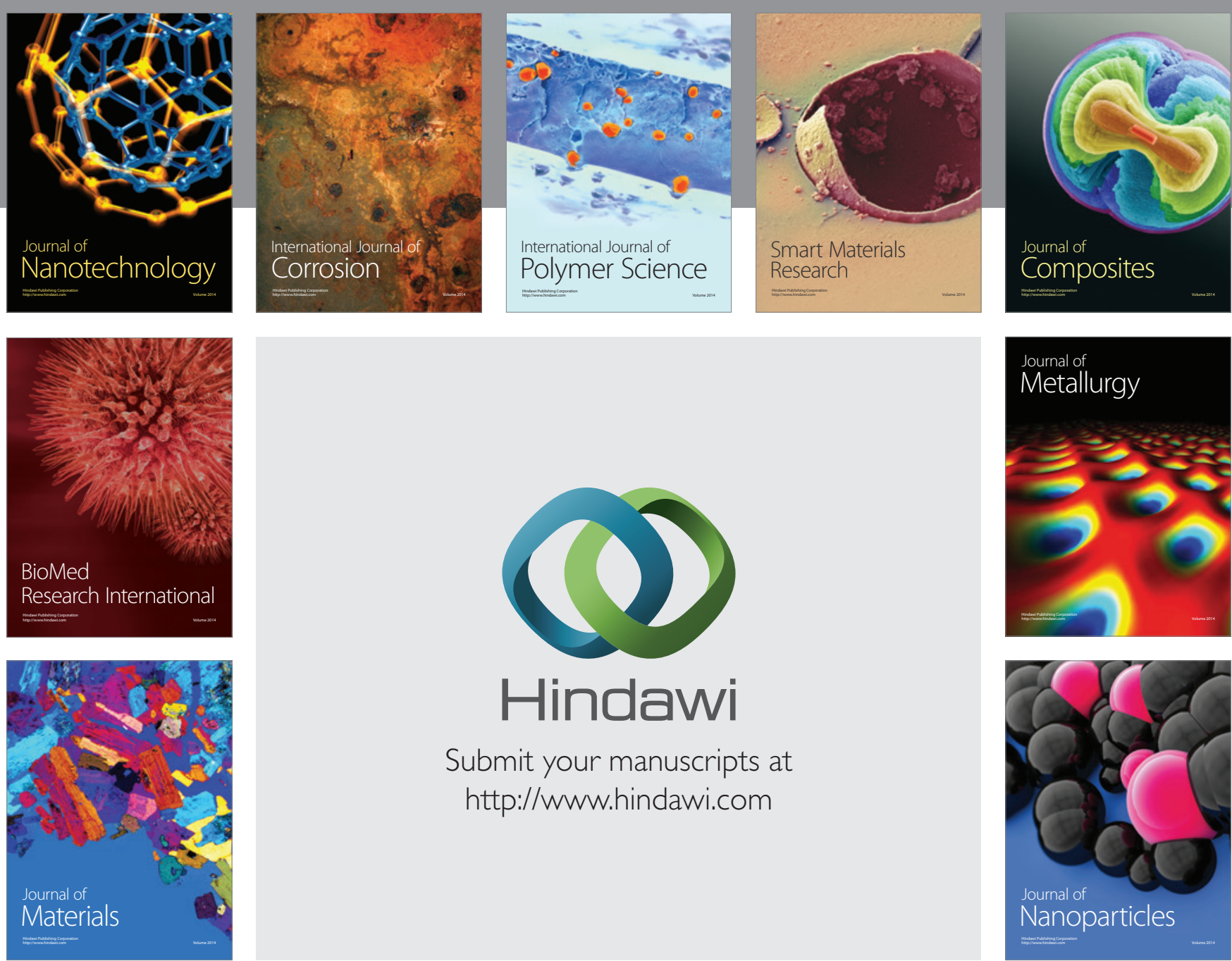

\section{Hindawi}

Submit your manuscripts at

http://www.hindawi.com

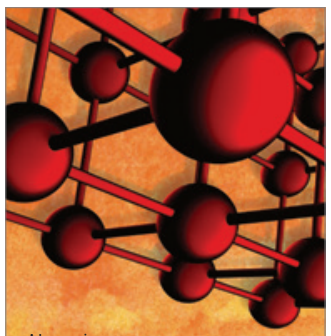

Materials Science and Engineering
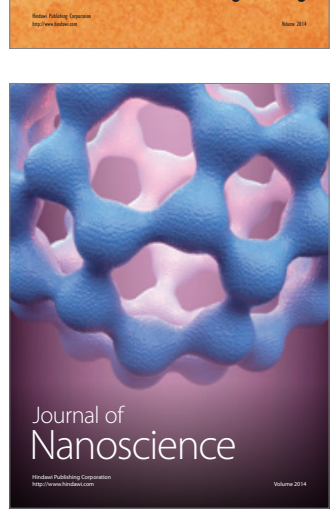
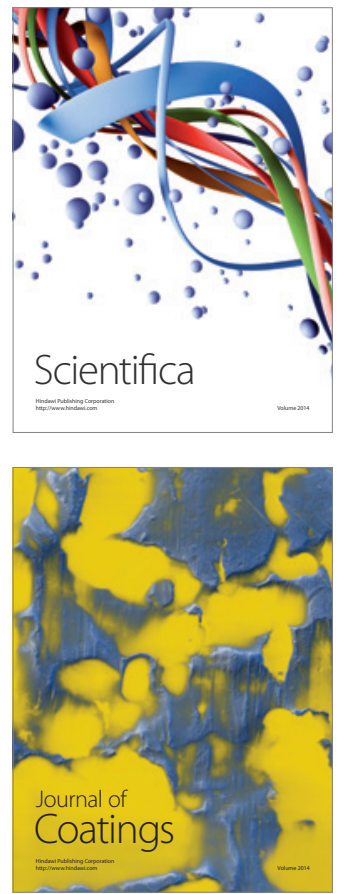
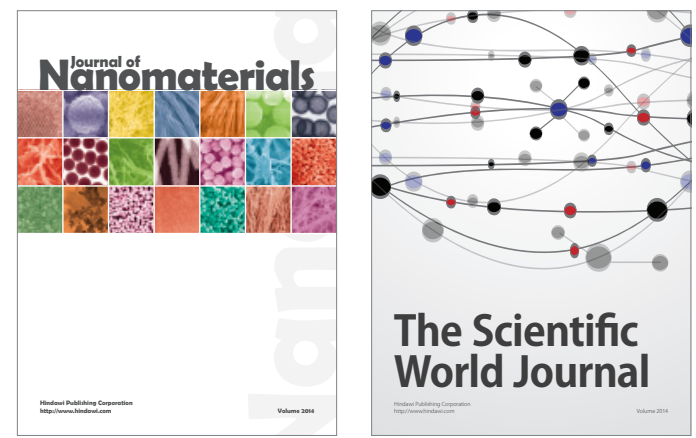

The Scientific World Journal
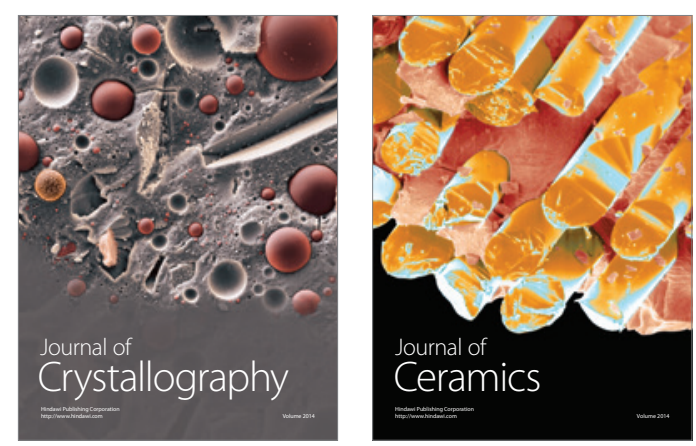
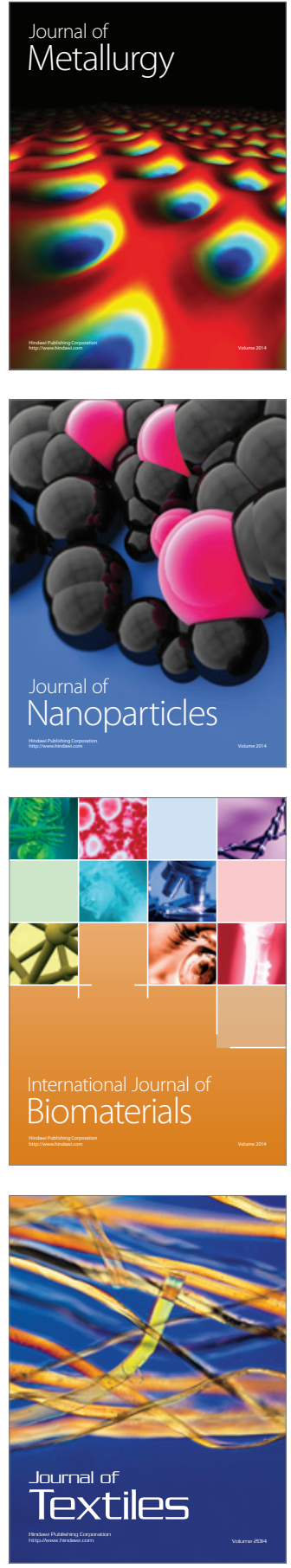